Voix et Images

volxetimages

\title{
Les Enfants du sabbat d'Anne Hébert
}

\section{Jacques Allard}

Volume 1, numéro 2, décembre 1975

\section{Raoul Duguay}

URI : https://id.erudit.org/iderudit/290080ar

DOI : https://doi.org/10.7202/290080ar

Aller au sommaire du numéro

Éditeur(s)

Les Presses de l'Université du Québec

ISSN

0318-9201 (imprimé)

1705-933X (numérique)

Découvrir la revue

Citer ce compte rendu

Allard, J. (1975). Compte rendu de [Les Enfants du sabbat d'Anne Hébert]. Voix et Images, 1(2), 285-286. https://doi.org/10.7202/290080ar

Ce document est protégé par la loi sur le droit d'auteur. L'utilisation des services d'Érudit (y compris la reproduction) est assujettie à sa politique d'utilisation que vous pouvez consulter en ligne.

https://apropos.erudit.org/fr/usagers/politique-dutilisation/
Cet article est diffusé et préservé par Érudit.

Érudit est un consortium interuniversitaire sans but lucratif composé de l’Université de Montréal, l’Université Laval et l'Université du Québec à Montréal. Il a pour mission la promotion et la valorisation de la recherche. https://www.erudit.org/fr/ 


\section{Les Enfants du sabbat d'Anne Hébert}

Sainte-Julie de la Trinité, fille du viol et de l'inceste, entends-nous, exauce-nous.

Aucun lecteur d'ici n'aura sans doute repris à son compte cette invocation diabolique qui a cours chez les dames du Précieux-Sang, telles que nous les présente $A$. Hébert dans son dernier roman'. Nous y retrouvons pourtant l'envers sabbatique (blasphématoire) de la magie catholique de notre enfance. Et la structuration narrative établie, comme dans Kamouraska, sur des “visions" (au sens cette fois plus mystique qu'onirique) génère une multiplicité de “voix" auxquelles même l'énonciation finit par succomber, la voix de la sorcière devenant parfois le seul support d'un discours d'envoûtement.

Cependant, pour que la magie discursive opère de façon aussi entière (et probablement utopique!) que le suggère ce préambule, il aurait fallu que nous retrouvions, constamment maintenu, le lyrisme si intense qui imprégnait l'écriture de Kamouraska. Or, nous avons affaire ici à une entreprise narrative mesurée, disciplinée. On en verra d'ailleurs un indice dans ce recours chez l'auteur aux classiques de la sorcellerie ${ }^{2}$ dont elle a tiré un juste parti, tout en se gardant bien d'en transformer les données (ce qui eût été risqué de toute manière, si l'on en juge par la mode lancée par l'Exorciste).

Marquer ainsi les lımites de l'impact discursif ne nie en rien le plaisir ou l'intérêt que l'on prend à lire ce roman, ne serait-ce que pour certaines de ses caractéristiques, comme nous l'illustrerons sommairement.

L'hıstoire de la fille d'Adélard et de Philomène se distribue en cinquante-troıs lexies (séparées par des espaces et non numérotées). On ne s'est peut-être pas arrêté suffisamment à cette procédure de découpage pratiquée déjà dans Kamouraska et reprise ici d'une façon identique. Ces unités de lecture ne sont visiblement pas des chapitres, mais des récits plutôt courts (d'une dizaine de lignes à une douzaine de pages) qui ont diverses fonctions au plan narratif. Elles peuvent, par exemple, isoler dans leur brièveté le moment final d'une séquence pour en grossir l'aboutissement (voir p. 61). Cet effet de grossissement est aussi fréquemment recherché dans le récit-tableau (Sœur Julie et ses maléfices à la cuisine, au

1. Paris, Éditions du Seuil, 1975, 187 pages.

2. On nous donne, en appendice, les titres de sept ouvrages consultés. 
repas, la nuit, pendant le sermon, etc.). Ailleurs, tel récit se présentera comme pure ponctuation (confirmation) d'une situation préalablement établie, et ne relancera aucunement l'anecdote (voir p. 49, alors que la réalité accrédite la visıon de la mort de l'Anglaise et de son enfant).

Et toujours, la brièveté de la lexie favorisera ce qu'on pourrast appeler le discours «poétique» tenu par cette forme romanesque: le montage parallèle de deux récits permet, avec ses transitıons parfois énonciatives, parfois thématiques - ou jusque dans ses ellipses, la fusion du présent et du passé, de l'ailleurs et de l'icı conventuel. Cette suite heurtée, brisée concentrée, disciplinée, ciselée ne fait que reproduire la structuration même de l'énoncé dans l'œuvre d'Anne Hébert. Le récit peut alors être vu comme l'expansion structurale du vers.

On constatera aussi que ce montage parallèle, qui se fait d'abord en mettant en conjonction deux lexies, en arrive bientôt à se manifester à l'intérieur d'une seule pour signaler à quel point le récit second pénètre et transforme le premier - le couvent étant peu à peu ensorcelé par la montagne (voir p. 34-45, lexie 8). De parallèle, le montage devient alors confluant. Et cet arrangement narratif ne se détache pas de celui de l'énonciation.

On trouve différentes instances ici, comme dans l'autre roman, qui correspondent aux points de vue. Ces "voix" peuvent se ramener à trois: la voix neutre (qui dit tout de même "Je", une fois); celle propre aux actants et celle plus curieuse qu'on pourrait appeler la voix “off ": voix de la conscience ou de l'intériorité, de Dieu ou du diable, de la communauté en tant que telle ou encore celle d'un spectateur anonyme de la communauté. Cette dernière interpelle, ordonne, provoque, condamne, etc., et dit "nous". Le jeu global de ces paroles évoque très souvent le dialogue théâtral ou cinématographique, quand ce n'est pas l'ensemble narratıf qui mime le texte dramatique, la représentatıon (reconstitution d'événements), avec annotations de mise en scène. Et, bien sûr, dans ce concert, celle de Julie reste déterminante puisqu'elle nous livre la visıon satanique et l'ımpose bientôt aux autres. Ce sont d'ailleurs ses visions qui dès l'incipit servent l'embrayage narratif, et autorisent la segmentation du récit en séquences.

Voilà quelques-unes des réflexions préliminaires que suscite la facture de ce nouveau livre. Beaucoup d'autres facettes ou niveaux de lecture sollicitent notre attention. Exemples: l'amour que porte Julie à son frère Joseph n'est pas sans rappeler celui de Bérénice (l'Avalée des avalés ${ }^{3}$ ) à l'égard de Christian; la thématique du secret progressıvement (mais jamais entièrement) dévoilé ; ou celle encore de l'enfermement. On pense aussi à cette autre communauté religieuse décrite par Adrien Thério dans les Fous d'amour ${ }^{4} .$.

3. Paris, Gallimard, 1966.

Jacques Allard

4. Montréal, Éditions Jumonville, 1973. 